\title{
A New Intelligent Method for Parallel Transmission Lines Protection
}

\author{
Amir Hossein Azimi $^{1}$ • Ali Akbar Abdoos ${ }^{1}$ (D)
}

Received: 21 February 2020 / Accepted: 19 July 2020 / Published online: 1 August 2020

(C) Springer Nature Singapore Pte Ltd. 2020

\begin{abstract}
In many countries, the parallel lines are widely used in transmission systems due to economic and technical benefits. Distance relays have poor performance on the protection of parallel transmission lines because of the mutual coupling effect. The distance relay may underreach when both lines are in-service. On the other hand the over reach problem may arise when only one line is in-service and another line is disconnected and grounded at both sides. Therefore, a new intelligent method is presented to protect parallel lines comprehensively in different operating modes. In the first stage, considering the status of circuit breakers as well as measured current signals at both sides of parallel lines, the fault types are identified by allocating a probabilistic neural network (PNN). Then, in the second stage, the fault location is estimated by assigning an artificial neural network (ANN) to each type of fault. The results obtained from the simulation of a part of the power system including $230-\mathrm{kV}$ parallel lines, show that the proposed method can accurately detect all fault types and also it can precisely locate the fault points with an accuracy of $98.8 \%$.
\end{abstract}

Keywords Parallel transmission line $\cdot$ Artificial intelligence $\cdot$ Mutual coupling $\cdot$ Distance protection

\section{Nomenclature}

$I_{z s 1 m} \quad$ amplitude of the faulty line zero sequence current at the sending side.

$I_{z r 1 m} \quad$ amplitude of the faulty line zero sequence current at the receiving side.

$I_{z s 2 m} \quad$ amplitude of the healthy line zero sequence current at the sending side.

$I_{z r 2 m} \quad$ amplitude of the healthy line zero sequence current at the receiving side.

$I_{n s 1 m} \quad$ amplitude of the faulty line negative sequence current at the sending side.

$I_{n r 1 m} \quad$ amplitude of the faulty line negative sequence current at the receiving side.

$I_{p s 1 m} \quad$ amplitude of the faulty line positive sequence current at the sending side.

$I_{p r 1 m} \quad$ amplitude of the faulty line positive sequence current at the receiving side.

Ali Akbar Abdoos

a.abdoos@nit.ac.ir

1 Department of Electrical and Computer Engineering, Babol Noshirvani University of Technology, Shariati Ave, Babol, Iran
$V_{n s 1 m} \quad$ amplitude of the faulty line negative sequence voltage at the sending side.

$V_{n r 1 m}$ amplitude of the faulty line negative sequence voltage at the receiving side.

$V_{p s 1 m} \quad$ amplitude of the faulty line positive sequence voltage at the sending side.

$V_{p r 1 m} \quad$ amplitude of the faulty line negative sequence voltage at the receiving side.

$I_{z s 1 p} \quad$ angle of the faulty line zero sequence current at the sending side.

$I_{z r 1 p} \quad$ angle of the faulty line zero sequence current at the receiving side.

$I_{z s 2 p} \quad$ angle of the healthy line zero sequence current at the sending side.

$I_{z r 2 p} \quad$ angle of the healthy line zero sequence current at the receiving side.

$I_{n s 1 p} \quad$ angle of the faulty line negative sequence current at the sending side.

$I_{n r 1 p} \quad$ angle of the faulty line negative sequence current at the receiving side.

$I_{p s 1 p} \quad$ angle of the faulty line positive sequence current at the sending side.

$I_{p r 1 p} \quad$ angle of the faulty line positive sequence current at the receiving side. 
$V_{n s 1 p} \quad$ angle of the faulty line negative sequence voltage at the sending side.

$V_{n r 1 p} \quad$ angle of the faulty line negative sequence voltage at the receiving side.

$V_{p s 1 p} \quad$ angle of the faulty line positive sequence voltage at the sending side.

$V_{p r 1 p} \quad$ angle of the faulty line negative sequence voltage at the receiving side.

\section{List of Abbreviations}

ANN Artificial Neural Network.

CT Current Transformer.

CVT Capacitor Voltage Transformer.

DFT Discrete Fourier Transform.

FSC Ferroresonance Suppression Circuit.

PDF Probabilistic Distribution Function.

PNN Probabilistic Neural Network.

WT Wavelet Transform.

\section{Introduction}

Installation and operation of parallel transmission lines are increasingly developing due to several advantages from different aspects such as power transfer capability, availability, environmental and economic factors.

Distance relays are the conventional protection of transmission lines but when used for the parallel lines protection, their performance is affected by mutual coupling effect. The distance relay may overreach when one of the lines is switched off and grounded at both sides. Moreover, the undereach problem may arise when both lines are operating in parallel [1]. Several methods have been presented for the protection of parallel transmission lines. One of the conventional protection schemes is a cross differential technique $[2,3]$. When one of the lines is ou-of-service and earthed on both ends, a cross differential protection scheme will not be useful because its performance is based on the comparison between currents of the same phases in the parallel circuits. Moreover, cross differential based techniques are not able to determine the fault locations. In some methods, traveling waves have been used for fast fault detection and location [4-8]. The main disadvantage of the travelling waves-based methods is that the protection scheme yields poor performance for faults close in faults.

Moreover, some intelligent methods have been presented for transmission line protection using artificial neural networks (ANNs) [9]. To improve the distance protection scheme for parallel lines protection, an ANN based method has been presented in [10] that could only detect single-phase to ground faults. In [11], an intelligent protective algorithm based on the phase comparator has been presented to detect directional earth fault without using the voltage signal. In [12], an ANN is used to estimate the entire power system conditions based on local measurements. The main drawback of these intelligent methods is that the fault type identification are not implemented.

In some other methods, the well-known signal processing tool i.e. wavelet transform (WT) is used to analyze measured signals to improve fault locator performance [13 and 14].

In [15], the mutual coupling of parallel lines are fully compensated by using the zero-sequence currents. In [16], a new algorithm has been developed only for detection of crosscountry non-earthed faults that occurs in the first zone of parallel lines. Authors presented a double-circuit distance protection for single line to ground faults while other fault types have been neglected in this study.

In this paper an intelligent method is presented for the parallel transmission line protection. The proposed method is composed of two important steps. In the first step, the fault type is determined by using the probabilistic neural network (PNN) which is trained based on the measured current signals at both sides as well as the status of circuit breakers. Then, in the second step, the fault location is estimated by using ANNs which are separately trained for each fault type. The proposed algorithm has some advantages from following viewpoints:

- The complete parallel lines protection is realized by implementation of both fault detection and fault location.

- All operating conditions of parallel lines are considered especially when the switched off line is grounded at both sides.

- All fault types are located with high accuracy due to selection of meaningful features.

- The proposed algorithm is very fast so that the fault location can be detected in less than $5 \mathrm{msec}$.

- Variable parameters such as fault resistance, fault type and fault location have negligible effect on the proposed algorithm accuracy.

- A separate ANN is utilized for estimation of the zero sequence current of the line which is disconnected and grounded at both sides.

- The transient behavior of current transformer (CT) and capacitor voltage transformer (CVT) does not degrade the performance of the proposed protection scheme.

\section{Need for a New Algorithm}

As mentioned in the introduction section, the distance relays have been designed to be the main protection of the transmission lines. The positive sequence impedance that is measured at the relay location form the operation basis of the distance protection, because it appears in all fault types [17-19]. In the parallel operating mode, when both lines are in-service, the relay input current should be compensated to calculate the 
positive sequence impedance, correctly. This is easily accomplished because both parallel line currents are accessible in this condition. The most challenging issue in parallel lines protection arises when one line is disconnected and grounded at both sides while a single phase to ground fault occurs on the line in-service. In this situation, the mutual zero sequence impedance appears in the sequence matrix while the current of disconnected line is not accessible due to the CT location in the substation. Thus, in this situation, the calculation of the positive sequence impedance at the relay location is impossible [17]. In the following, the fault location for parallel transmission lines based on the distance protection scheme is briefly discussed in different operating conditions.

When one line is disconnected at one end or it is disconnected at both ends and not grounded, the line in-service can be considered as a single circuit line because no current can pass through disconnected line. Thus, the same conventional distance protection algorithm can be applied while the positive sequence impedance is calculated as given in eq. (1) $[17,19]$ :

$p Z_{1}=\frac{V_{a x}}{I_{a x}+K_{0} I_{x 0}}$

where $K_{0}=\left(Z_{0}-Z_{1}\right) / Z_{1}$.

On the other hand, when both parallel lines are in-service, eq. (1) can be used for calculation of the positive sequence impedance when the single line to ground fault occurs on the line in-service. The following modification is made to the relay input current because of the zero sequence coupling between parallel lines [17].

$p Z_{1}=\frac{V_{a x}}{I_{a x}+K_{0} I_{x 0}+K_{M} I_{y 0}}$

where $K_{M}=Z_{m 0} / Z_{1}$,

$V_{a x}$ : faulty phase voltage,

$I_{a x}$ : faulty phase current,

$I_{x 0}$ : faulty line zero sequence current,

$I_{y 0}$ : adjacent line zero sequence current,

$Z_{0}$ : zero sequence impedance of the line,

$Z_{1}$ : posetive sequence impedance of the line,

$Z_{m 0}$ : zero sequence mutual coupling impedance of the parallel lines.

Thus, access to zero sequence current of adjacent line is necessary for the calculation of the positive sequence impedance at the relay location. Since both lines are in-service, CTs are able to measure the line currents so that $I_{x 0}$ and $I_{y 0}$ can be easily calculated.

In the next operating mode, as shown in Fig. 1, line $\mathrm{Y}$ is disconnected and grounded at both ends while a single line to ground fault occurs on the line $\mathrm{X}$ which is in-service. For this condition, the corresponding zero sequence circuit connection of parallel lines is as shown in Fig. 2. In this situation, the zero sequence current of the disconnected line i.e. $I_{y 0}$ is not accessible because CTs are located behind the circuit breakers. According to zero sequence circuit of parallel lines in Fig. 2, $I_{y 0}$ can be found as follows [17]:

$I_{y 0}=\frac{Z_{m 0}\left\{(1-p) Z_{s 0}-Z_{r 0}\right)}{Z_{0}\left\{(1-p) Z_{0}+Z_{r 0}\right\}-(1-p) Z_{m 0}^{2}} I_{x 0}$

where $Z_{s 0}$ and $Z_{r 0}$ are zero sequence impedances of power supplies at both sides of lines and $p$ is the fault location in percent. As can be seen in equation (3), $I_{y 0}$ is dependent on the fault location (p) and the zero sequence impedances of power supplies $\left(Z_{s 0}, Z_{r 0}\right)$.

It should be noted that the fault location is unknown and also source impedances can be changed according to the network topology and power system operation. Moreover, the fault resistance can affect the zero sequence current of the faulty line and consequently can impact on the zero sequence current of the adjacent line. It should be noted that $I_{y 0}$ as calculated in (3) is a function of the fault location (p) that is the main unknown of the problem. Thus, the calculation of the positive sequence impedance of the faulty line is not possible by using equations (1) and (3). Therefore, based on the given descriptions in this section, a new algorithm for fault location is an urgent necessity to protect parallel lines under different operational conditions.

\section{Proposed Method}

As described in section 2, the inefficiency of the conventional distance protection has been justified for parallel lines protection. The main difficulty arises when one of the circuit is disconnected and grounded at both sides. In this study, a two-stage intelligent method is designed in order to propose a comprehensive protection scheme. At the first stage, the
Fig. 1 A single-phase to ground fault in parallel lines when one of the line is out-of-service and grounded at both ends [17]

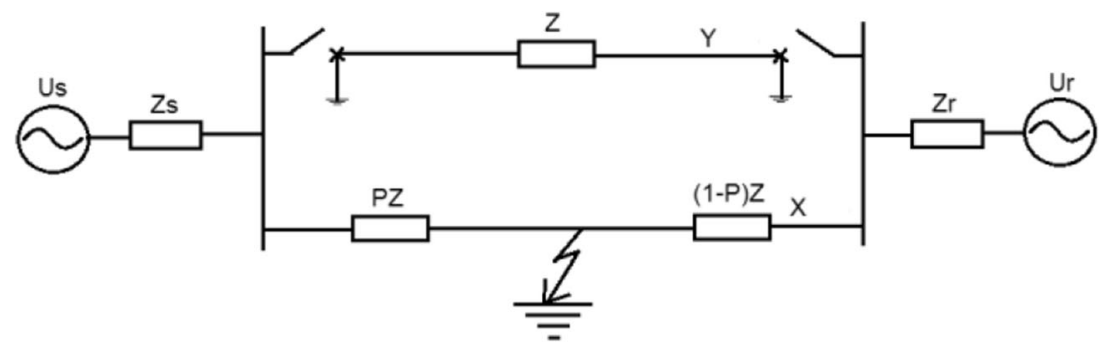


Fig. 2 Zero sequence circuit connection for the single phase to ground fault depicted in Fig. 1 [17]

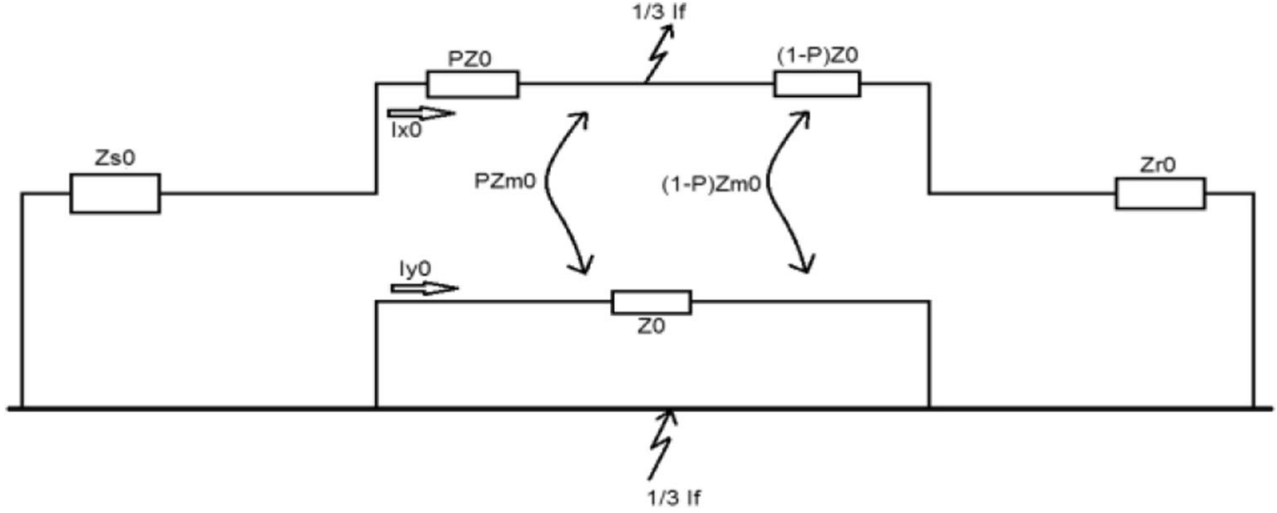

fault detection is performed and in the second stage the fault location is realized through measurement currents at both sides. In the following subsections, each stage is described in details.

\section{Fault Type Classification}

In order to detect the fault type in parallel lines protection, the measured currents at both sides are very helpful as used in line differential protection schemes $[3,4]$. Due to access to both sides' currents of the line in-service, the angle and magnitude of measured currents can be easily obtained by using discrete Fourier transform (DFT). The current angle difference of each phase forms the elements of input vectors of the exemplar patterns [20].

When the lines are in the normal situation, the angle difference between measured currents of the same phase of each line at both sides is about 180 degrees. The main reason of this difference is the currents direction at both sides of the line. The simulation results prove that under different conditions, the angle difference between same phases remains about 180 degrees. On the other hand, during fault conditions, the angle difference is no longer near 180 degrees due to the change of current direction. However, healthy phases still are maintained 180 degree angle difference. When a fault occurs outside of the under protection line, the angle difference is near to the 180 degree and the algorithm does not identify any fault. Therefore, one of the great advantages of the proposed intelligent fault detection scheme is the removal of relay overreaching which is an important matter for protection of parallel lines. In addition, when an earth fault occurs on the transmission line, the zero sequence current will appear in the sequences equivalent circuit. Thus, the zero sequence current can be used as a meaningful feature for detection of earth faults. For this reason, magnitudes of zero sequence currents of both lines in-service are used as other important features to determine whether the fault involves earth or not.

In the proposed intelligent fault detection method, the wellknown classifier i.e. PNN is used as the detection core to identify the fault type. PNN estimates the class probability of an input vector using the probabilistic density function (PDF) of each class and then the class with the highest posterior probability is allocated based on Bayes' rule. Since the fast clearance time of faults has a great impact on power system stability, the proposed fault detection is of great importance. The proposed fault detection method is able to detect the fault in about $5 \mathrm{msec}$. This time is the interval between preparing input data to ANN and the instant the decision is made by ANN as the output.

Overall, eight features are considered for each input vector. Six of them are related to the current angle difference of each phase and two features are zero-sequence current measured at the relay location. PNN outputs are labelled with 21 different classes as given in Table 1. It should be noted that when one of the lines is out-of-service and grounded on both ends (this situation can be detected based on status of circuit breakers), another PNN is used for fault type detection. This PNN is separately trained by only 4 inputs including the current angle difference of three phases of the line in-service as well as the corresponding zero sequence current magnitude. The outputs of this PNN are the first eleven classes specified in Table 1.

Table 1 Class number of each fault type

\begin{tabular}{lclc}
\hline Fault Type & Class Number & Fault Type & Class Number \\
\hline Normal condition & 1 & A2-G & 12 \\
A1-G & 2 & B2-C2-G & 13 \\
B1-C1-G & 3 & B2-C2 & 14 \\
B1-C1 & 4 & A2-B2-C2 & 15 \\
A1-B1-C1 & 5 & B2-G & 16 \\
B1-G & 6 & A2-C2-G & 17 \\
A1-C1-G & 7 & A2-C2 & 18 \\
A1-C1 & 8 & C2-G & 19 \\
C1-G & 9 & A2-B2-G & 20 \\
A1-B1-G & 10 & A2-B2 & 21 \\
A1-B1 & 11 & & \\
\hline
\end{tabular}


Table 2 Inputs, outputs and the number of required ANNs when both lines are in-service

\begin{tabular}{llll}
\hline Fault type & $\begin{array}{l}\text { Number of } \\
\text { required ANN }\end{array}$ & First network inputs & $\begin{array}{l}\text { First network } \\
\text { outputs }\end{array}$ \\
\hline Single-phase to ground & 1 & $I_{z s 1 m}, I_{z s 1 p}, I_{z r 1 m}, I_{z r 1 p}, I_{z s 2 m}, I_{z s 2 p}, I_{z r 2 m}, I_{z r 2 p}$ & Fault location \\
Two-phase to ground & 1 & $I_{z s 1 m}, I_{z s 1 p}, I_{z r 1 m}, I_{z r 1 p}, I_{z s 2 m}, I_{z s 2 p}, I_{z r 2 m}, I_{z r 2 p}$ & Fault location \\
Phase to phase & 1 & $V_{p s 1 m}, V_{p s 1 p}, V_{p r 1 m}, V_{p r 1 p}, I_{p s 1 m}, I_{p s 1 p}, I_{p r 1 m}, I_{p r 1 p}$ & Fault location \\
& & $V_{n s 1 m}, V_{n s 1 p}, V_{n r 1 m}, V_{n r 1 p}, I_{n s 1 m}, I_{n s 1 p}, I_{n r 1 m}, I_{n r 1 p}$ & \\
Three-phase & 1 & $V_{p s 1 m}, V_{p s 1 p}, V_{p r 1 m}, V_{p r 1 p}, I_{p s 1 m}, I_{p s 1 p}, I_{p r 1 m}, I_{p r 1 p}$ & Fault location \\
\hline
\end{tabular}

\section{Estimation of Fault Location}

To completely protect the transmission line, after fault type determination, it is necessary to find the fault location. It should be emphasized that the fault location in parallel line is very complicated due to mutual induction between two circuits. Moreover, operating modes of parallel lines can affect the fault location scheme. So, in this study, the nonlinear relation between fault location and available measured signals is discovered by an intelligent tools.

For each fault type, a separate ANN is used to find the fault location. The required number of ANNs for each fault type as well as the related inputs are given separately in Tables 2 and 3 for both operating modes of the protected line. The utilized parameters in these tables are described in the appendix. The reason for choosing these special inputs is the dependency of sequence currents on the fault type. In fact, the selected inputs depend heavily on the sequence circuit during fault conditions.

When parallel lines are in-service, for both singlephase to ground and double-phase to ground faults, zero sequence currents appear in the sequence circuit of both lines. Besides, only zero sequence mutual coupling impedance appears in the sequence impedance matrix of parallel lines. As a result, when ground faults occur, the impedance seen by the relay is affected by the zero sequence current of adjacent line.

On the other hand, the zero sequence currents can be helpful for estimation of fault location. Since the current measurement is possible for both parallel lines in-service, the amplitude and phase of the zero-sequence currents of both sides of two parallel lines are used as meaningful features to find the fault location. As depicted in Table 2, the magnitude and phase of zero sequence current of both lines $\left(I_{z s 1 m}, I_{z s 1 p}\right.$, $\left.I_{z r 1 m}, I_{z r 1 p}, I_{z s 2 m}, I_{z s 2 p}, I_{z r 2 m}, I_{z r 2 p}\right)$ are utilized for fault location.

When one of the parallel lines is out-of-service and grounded at both sides, the line current measurement is not possible due to the location of CTs. In this condition, in order to have an accurate estimation of the fault location, the zero sequence current of the out-of-service line is predicted by an ANN. In this paper, because of the zero sequence mutual impedance between parallel lines, the zero sequence current of the line inservice $\left(I_{z s 1 m}, I_{z s 1 p}, I_{z r 1 m}, I_{z r 1 p}\right)$ is used as input of the ANN for the estimation of the zero sequence current of the adjacent line $\left(I_{z s 2 m}, I_{z s 2 p}\right)$.

Moreover, since the induced current is rather identical along the out-of-service line, the estimation of zero sequence current from one side is sufficient. Therefore, two separate ANNs are needed to predict the amplitude and angle of the

Table 3 Inputs, outputs and the number of required ANNs when a line is out-of-service and grounded on both ends

\begin{tabular}{|c|c|c|c|c|c|c|c|}
\hline Fault type & $\begin{array}{l}\text { Number of } \\
\text { required ANNs }\end{array}$ & 1st network inputs & $\begin{array}{l}1 \text { st network } \\
\text { outputs }\end{array}$ & $\begin{array}{l}\text { 2nd network } \\
\text { inputs }\end{array}$ & $\begin{array}{l}\text { 2nd network } \\
\text { outputs }\end{array}$ & 3rd network inputs & $\begin{array}{l}\text { 3rd network } \\
\text { output }\end{array}$ \\
\hline $\begin{array}{l}\text { Single-phase } \\
\text { to ground }\end{array}$ & 3 & $I_{z s 1 m}, I_{z s 1 p}, I_{z r 1 m}, I_{z r 1 p}$ & $I_{z s 2 m}$ & $\begin{array}{l}I_{z s 1 m}, I_{z s 1 p}, \\
\quad I_{z r 1 m}, I_{z r 1 p}\end{array}$ & $I_{z s 2 p}$ & $\begin{array}{l}I_{z s 1 m}, I_{z s 1 p}, I_{z r 1 m} \\
\quad I_{z r 1 p}, I_{z s 2 m}, I_{z s 2 p}\end{array}$ & $\begin{array}{l}\text { Fault } \\
\text { location }\end{array}$ \\
\hline $\begin{array}{l}\text { Two-phase to } \\
\text { ground }\end{array}$ & 3 & $I_{z s 1 m}, I_{z s 1 p}, I_{z r 1 m}, I_{z r 1 p}$ & $I_{z s 2 m}$ & $\begin{array}{l}I_{z s 1 m}, I_{z s 1 p}, \\
\quad I_{z r 1 m}, I_{z r 1 p}\end{array}$ & $I_{z s 2 p}$ & $\begin{array}{l}I_{z s 1 m}, I_{z s 1 p}, I_{z r 1 m} \\
\quad I_{z r 1 p}, I_{z s 2 m}, I_{z s 2 p}\end{array}$ & $\begin{array}{l}\text { Fault } \\
\text { location }\end{array}$ \\
\hline Phase to phase & 1 & $\begin{array}{l}V_{p s 1 m}, V_{p s 1 p}, \\
V_{p r 1 m}, V_{p r 1 p}, \\
I_{p s 1 m}, I_{p s 1 p}, \\
I_{p r 1 m}, I_{p r 1 p}, \\
V_{n s 1 m}, V_{n s 1 p}, V_{n r 1 m}, V_{n r 1 p}, \\
\quad I_{n s 1 m}, I_{n s 1 p}, I_{n r 1 m}, I_{n r 1 p}\end{array}$ & $\begin{array}{l}\text { Fault } \\
\quad \text { location }\end{array}$ & - & - & - & - \\
\hline Three-phase & 1 & $\begin{array}{l}V_{p s 1 m}, V_{p s 1 p}, V_{p r 1 m}, V_{p r 1 p} \\
\quad I_{p s 1 m}, I_{p s 1 p}, \\
I_{p r 1 m}, I_{p r 1 p}\end{array}$ & $\begin{array}{l}\text { Fault } \\
\text { location }\end{array}$ & - & - & - & - \\
\hline
\end{tabular}


Fig. 3 Flowchart of the proposed algorithm

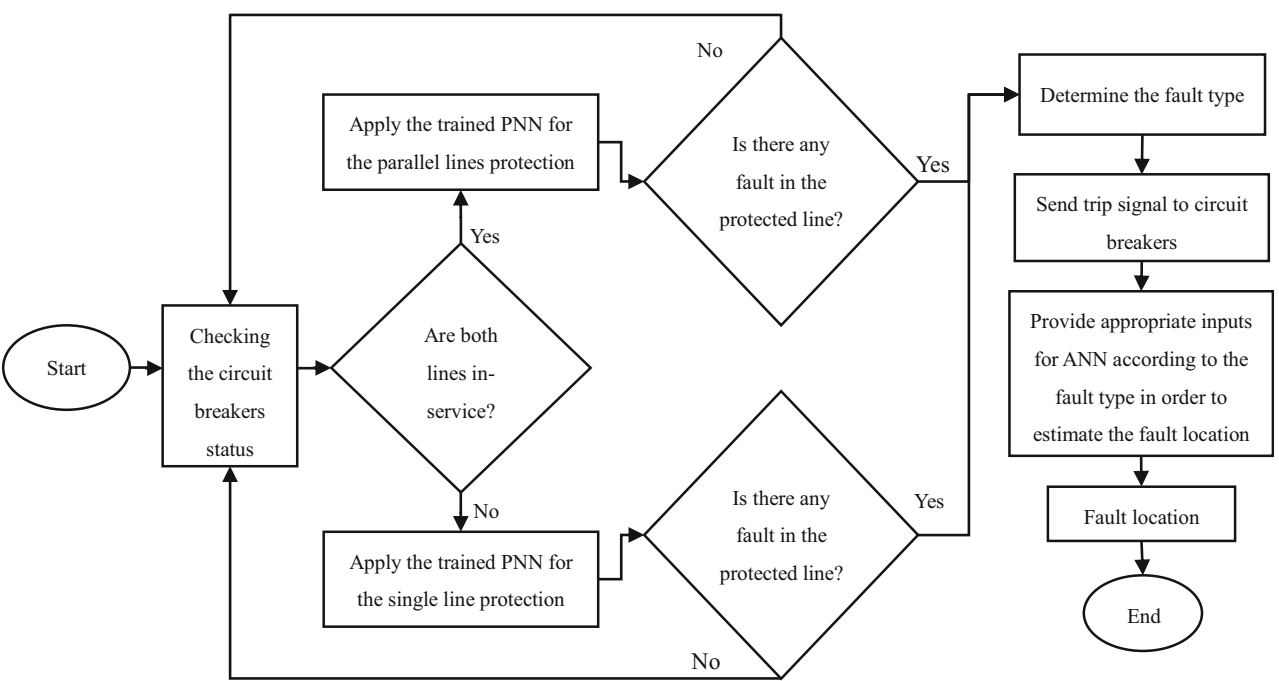

zero sequence current of the adjacent line (Table 3, rows 1 and $2)$. As given in Table 3 , the output of these two ANNs $\left(I_{z s 2 m}\right.$, $\left.I_{z s 2 p}\right)$ as well as the measured currents at both sides of the line in-service $\left(I_{z s 1 m}, I_{z s 1 p}, I_{z r 1 m}, I_{z r 1 p}\right)$ form the elements of the input vector of third ANN for ground fault location (Table 3, rows 1 and 2). Thus, three ANNs are required for fault location detection when ground faults occur.

For both operating modes of parallel lines, positive and negative sequence currents appear when a phase-to-phase fault occurs. For this fault type, the zero sequence current does not appear and consequently no current is induced in the outof-service line. In order to estimate the fault location, the positive and negative sequence current $\left(I_{p s 1 m}, I_{p s 1 p}, I_{p r 1 m}\right.$, $I_{p r 1 p}, I_{n s 1 m}, I_{n s 1 p}, I_{n r 1 m}, I_{n r 1 p}$ ) as well as positive and negative sequence voltage of both sides of the faulty line $\left(V_{p s 1 m}\right.$, $\left.V_{p s 1 p}, V_{p r 1 m}, V_{p r 1 p}, V_{n s 1 m}, V_{n s 1 p}, V_{n r 1 m}, V_{n r 1 p}\right)$ are used as the ANN inputs (Tables 2 and 3, row 3). When a threephase fault happens, only positive sequence appears in the sequences equivalent circuit. For this reason, positive sequence voltage $\left(V_{p s 1 m}, V_{p s 1 p}, V_{p r 1 m}, V_{p r 1 p}\right)$ and current
$\left(I_{p s 1 m}, I_{p s 1 p}, I_{p r 1 m}, I_{p r 1 p}\right)$ of both sides of the faulty line are used as the inputs of the ANN (Tables 2 and 3, row 4).

In order to determine the fault location, the selection logic of ANNs' inputs is inspired by the distance relay. The distance relay calculates the positive sequence impedance based on the equivalent sequence circuit. Therefore, selected inputs for training of ANNs are dependent to fault type. Moreover, according to the parallel lines operating modes, the appropriate inputs are provided for each ANN. The flowchart of the proposed algorithm is shown in Fig. 3. At first, the status of the circuit breaker is checked and then the corresponding trained PNN is used for fault type detection. Then, according to the fault type, the corresponding ANN is utilized for the estimation of the fault location. It should be noted that the zero sequence current of the grounded switched-off line is required to determine the fault location accurately, so it is estimated using some additional ANNs according to Table 3. The output of these ANNs includes the magnitude and phase of the zero sequence current of the line that is out-of-service and grounded at both sides.
Table 4 Part of simulation results when both lines are in-service

\begin{tabular}{llllllll}
\hline Fault type & $\begin{array}{l}\text { Fault } \\
\text { location } \\
(\mathrm{km})\end{array}$ & $\begin{array}{l}\text { Fault } \\
\text { resistance } \\
(\mathrm{ohm})\end{array}$ & $\begin{array}{l}\text { Sources } \\
\text { difference } \\
\text { angle }\end{array}$ & $\begin{array}{l}\text { Fault class } \\
\text { detected by } \\
\text { PNN }\end{array}$ & $\begin{array}{l}\text { Fault } \\
\text { type } \\
\text { detection }\end{array}$ & $\begin{array}{l}\text { Predicted } \\
\text { fault } \\
\text { location } \\
(\mathrm{km})\end{array}$ & $\begin{array}{l}\text { Estimation } \\
\text { error } \\
\text { (Percentage) }\end{array}$ \\
\hline A1-G & 13 & 10 & 10 & 2 & $\sqrt{ }$ & 12.76 & 1.84 \\
B2-G & 52 & 25 & 25 & 16 & $\sqrt{ }$ & 52.18 & 0.34 \\
C1-G & 102 & 10 & 10 & 1 & $\sqrt{ }$ & - & - \\
A1-B1 & 39 & 15 & 25 & 11 & $\sqrt{ }$ & 38.90 & 0.25 \\
B1-C1-G & 52 & 20 & 10 & 3 & $\sqrt{ }$ & 51.48 & 1 \\
A2-B2-C2 & 91 & 15 & 30 & 15 & $\sqrt{ }$ & 90.86 & 0.15 \\
A2-C2-G & 26 & 30 & 25 & 17 & $\sqrt{ }$ & 26.58 & 2.23 \\
B2-C2 & 65 & 10 & 5 & 14 & $\sqrt{ }$ & 64.77 & 0.35 \\
A2-B2-G & 13 & 25 & 15 & 20 & $\sqrt{ }$ & 13.48 & 3.69 \\
\hline
\end{tabular}


Table 5 Average error in $\mathrm{km}$ for fault location estimation when both lines are in-service

\begin{tabular}{llllllll}
\hline $\begin{array}{l}\text { Fault location }(\mathrm{km}) \\
\text { Fault type }\end{array}$ & 13 & 26 & 39 & 52 & 65 & 78 & 91 \\
\hline Single-phase to ground & 0.855 & 0.004 & 0.002 & 0.112 & 0.001 & 0.002 & 0.270 \\
Two-phase to ground & 0.602 & 0.007 & 0.003 & 0.098 & 0.003 & 0.005 & 0.341 \\
Two-phase together & 0.027 & 0.004 & 0.001 & 0.001 & 0.001 & 0.003 & 0.077 \\
Three phase & 0.041 & 0.002 & 0.002 & 0.001 & 0.001 & 0.007 & 0.162 \\
\hline
\end{tabular}

\section{Discussion}

\section{Evaluation of the Proposed Method}

In order to evaluate the performance of the proposed protection scheme for parallel lines, a part of real power system is considered for simulation studies. The test case includes two parallel lines with length of $100 \mathrm{~km}$ as well as two $230 \mathrm{kV}$ sources with Thevenin impedance at both ends. The parallel lines structure is shown in Fig. 4 in appendix section. Two important operating modes of parallel lines are simulated in the PSCAD/EMTDC environment [21]. In one of the operating modes, both lines are in-service and in another mode, one of the lines is switched off and grounded at both ends. All fault types are applied to seven points of the protected line while fault resistances of $0,5,10,15,20,25$ and $30 \Omega$ are taken into account for each fault type. Moreover, six different values of angle difference between power supplies are considered i.e. $5,10,15,20,25,30$ degrees. Totally, 294 different cases are simulated for each type of fault in each operating mode of parallel lines. In the proposed method, fault location estimation is implemented based on the assumption that the fault type is determined in the first step. For this reason, more than 2000 cases are simulated and tested for evaluation of the fault type detector. In the first stage of the proposed method, the direction of lines current is used for fault type and faulty phase identification. In this way, the relay overreacheaing is avoided when fault occurs beyond the protected line.
As investigated in section 3, the logic behind the selection of inputs for fault location estimation is based on the sequence network. The simulation results are presented in Tables 4 and 5 when both lines are in-service. Moreover, in Tables 6 and 7 , the results are presented for the situation in which one of the lines is out-of-service and grounded at both sides. The performance of the proposed method has been investigated for different fault conditions and some parts of obtained results are provided in Tables 4 and 6 . In the presented results in Tables 4 and 6 , it was checked whether the fault type and faulty phase are correctly detected or not and also the estimated fault location is reported in the last column. As it can be seen in Tables 4 and 6, all fault types are detected correctly in the first step. In the second step of the proposed algorithm, the results related to fault location estimation are presented in Tables 5 and 7. Various fault types which occur on seven different points of the line as well as more than 20 different fault resistances and sources angle difference are considered in the simulation studies. The average error of the proposed fault location scheme is given in Tables 5 and 7 for two simulated operating modes of parallel lines. It can be seen that for ground faults (single phase to ground and two phase to ground) the average error for faults near two ends are greater than those of at the middle of the line. This is due to the fact that close-in ground faults are fed from both sides so that the close source injects a greater zero sequence currant than the farther source. Therefore, the estimation of the zero sequence current of the adjacent line may be prone to a higher error due to the small zero sequence current from the far end.
Table 6 Part of simulation results when one of the line is out-ofservice and grounded at both ends

\begin{tabular}{lllllllc}
\hline Fault type & $\begin{array}{l}\text { Fault } \\
\text { location } \\
(\mathrm{km})\end{array}$ & $\begin{array}{l}\text { Fault } \\
\text { resistance } \\
(\mathrm{ohm})\end{array}$ & $\begin{array}{l}\text { Sources } \\
\text { difference } \\
\text { angle }\end{array}$ & $\begin{array}{l}\text { Fault class } \\
\text { detected by } \\
\text { PNN }\end{array}$ & $\begin{array}{l}\text { Fault } \\
\text { type } \\
\text { detection }\end{array}$ & $\begin{array}{l}\text { Predicted } \\
\text { fault } \\
\text { location } \\
(\mathrm{km})\end{array}$ & $\begin{array}{l}\text { Estimation } \\
\text { error } \\
\text { (Percentage) }\end{array}$ \\
\hline B1-C1-G & 13 & 10 & 5 & 3 & $\sqrt{ }$ & 13.64 & 4.92 \\
A1-C1 & 39 & 15 & 10 & 8 & $\sqrt{ }$ & 38.41 & 1.51 \\
A1-G & 52 & 20 & 10 & 2 & $\sqrt{ }$ & 52.11 & 0.21 \\
B1-C1 & 110 & 15 & 25 & 1 & $\sqrt{ }$ & - & - \\
A1-B1-C1 & 26 & 5 & 5 & 5 & $\sqrt{ }$ & 26.00 & 0 \\
A1-B1 & 78 & 5 & 20 & 11 & $\sqrt{ }$ & 78.82 & 1.05 \\
A1-C1-G & 65 & 30 & 15 & 7 & $\sqrt{ }$ & 65.10 & 0.15 \\
B1-G & 91 & 25 & 15 & 6 & $\sqrt{ }$ & 90.54 & 0.5 \\
\hline
\end{tabular}


Table 7 Average error in $\mathrm{km}$ for fault location estimation when the disconnected line is grounded at both ends

\begin{tabular}{llllllll}
\hline $\begin{array}{l}\text { Fault location(km) } \\
\text { Fault type }\end{array}$ & 13 & 26 & 39 & 52 & 65 & 78 & 91 \\
\hline Single-phase to ground & 0.508 & 0.021 & 0.027 & 0.161 & 0.020 & 0.039 & 0.227 \\
Two-phase to ground & 0.654 & 0.027 & 0.021 & 0.223 & 0.025 & 0.043 & 0.165 \\
Two-phase together & 0.282 & 0.024 & 0.01 & 0.012 & 0.024 & 0.018 & 0.132 \\
Three phase & 0.388 & 0.027 & 0.014 & 0.042 & 0.008 & 0.027 & 0.159 \\
\hline
\end{tabular}

The obtained results show that the maximum average error for estimation of the fault location is about $0.855 \mathrm{~km}$ and the minimum error is $0.001 \mathrm{~km}$. According to Tables 4 and 6 , it is clearly seen that the proposed method can correctly detect the faulty phase and fault type. Moreover, the external fault i.e. $\mathrm{C} 1-\mathrm{G}$ at $102 \mathrm{~km}$ from the relay location can be detected accurately in both operating modes of parallel lines. Also, the last column of Tables 4 and 6 shows that the maximum estimation error of the proposed fault location is less than $5 \%$. The average percentage error given in the last column of Tables 4 and 6 is about $1.23 \%$ and $1.19 \%$ when both line are in-service and when the switched off line is grounded at both sides, respectively.

In Table 8, the proposed algorithm performance is compared to some methods which have been presented for parallel lines protection in recent years. In several papers, ANNs as a powerful intelligent tool have been used in various ways [9-12]. In most articles, attempts have been made to improve the conventional distance protection operation from aspect of either fault detection or fault location. But, in the proposed intelligent method fault detection and fault location are done simultaneously in separate stages while two main operating modes of parallel lines are considered. In some papers $[8,10$, $11,15,16]$, the fault type and the faulty phases are not identified and the protection schemes have been founded based on prior knowledge of the fault type. In most of these papers, the protection methods have been presented only for fault location in the case of single-phase to ground faults $[10,15]$ while in the first step of the proposed method, the fault type and faulty phases are detected. Besides, in some articles [7, 15, 16], some effective factors on parallel lines protection schemes have been neglected such as line capacitance, fault resistance, angle differences between sources and etc., but in this research, all above mentioned parameters are considered in the simulation studies. Another important attribute of our proposed fault location scheme is that, the simulation studies include the single line to ground faults when switched off line is grounded on both ends. This important situation has been neglected in many previously published paper [5, 9-12, 15-17] and they are applicable when both line are in-service and the current signals are measurable.

In additions, Table 8 provides comparison results from view point of estimation accuracy of fault location for some methods. Table 8 shows that the estimation accuracy of the fault locators presented in $[12,15,16]$ is less than $95 \%$ while our proposed intelligent method is able to estimate the fault location with accuracy of $100 \%$. Besides, the proposed method can detect all fault types unlike Refs $[10,15,16]$ which are not equipped with fault detection scheme. It is worth noting that the high accuracy of fault location estimation is the main advantage of the proposed method in comparison with the mentioned methods in Table 8. In the proposed method, the fault detection accuracy is $100 \%$ and the fault location estimation accuracy is $98.8 \%$.

\section{Performance Evaluation Considering CT \& CVT Errors}

In the real power systems, two important measurement tools i.e. CT and CVT provide the current and voltage signals for protective relays, respectively. For line protection, the CT of TPY class are usually is utilized because it has very low remnant flux about less than $10 \%$ of the nominal value. Thus, during reclosing process, the probability of $\mathrm{CT}$ saturation decreases significantly, but the ratio and phase errors still exist because of magnetizing and losses currents. These errors increase during fault conditions and can adversely affect the

Table 8 Comparison of the proposed method with the some papers

\begin{tabular}{|c|c|c|c|c|c|}
\hline Papers & $\begin{array}{l}\text { Detection } \\
\text { algorithm }\end{array}$ & Fault type detection & $\begin{array}{l}\text { Considering } \\
\text { effective } \\
\text { parameters }\end{array}$ & $\begin{array}{l}\text { Detection } \\
\text { accuracy of } \\
\text { fault type }\end{array}$ & $\begin{array}{l}\text { Estimation } \\
\text { accuracy of } \\
\text { fault location }\end{array}$ \\
\hline Ref. [10] & ANN & Single-phase to ground fault & $\sqrt{ }$ & - & $92 \%$ \\
\hline Ref. [15] & Modified Distances & Single-phase to ground fault & - & - & $90 \%$ \\
\hline Ref. [16] & Modified Distances & Non-grounded faults & $\sqrt{ }$ & - & $95 \%$ \\
\hline Proposed method & ANN & All types of faults & $\sqrt{ }$ & $100 \%$ & $98.8 \%$ \\
\hline
\end{tabular}


Table 9 The mean absolute percentage error for operating mode in which one line is disconnected and grounded at both sides considering CT and CVT errors

\begin{tabular}{|c|c|c|c|c|c|c|c|c|c|c|c|c|c|c|}
\hline \multirow{2}{*}{$\begin{array}{l}\text { Fault } \\
\text { location }(\mathrm{km}) \\
\text { Fault type }\end{array}$} & \multicolumn{2}{|l|}{13} & \multicolumn{2}{|l|}{26} & \multicolumn{2}{|l|}{39} & \multicolumn{2}{|l|}{52} & \multicolumn{2}{|l|}{65} & \multicolumn{2}{|l|}{78} & \multicolumn{2}{|l|}{91} \\
\hline & $\begin{array}{l}\text { With } \\
\text { error }\end{array}$ & $\begin{array}{l}\text { Without } \\
\text { error }\end{array}$ & $\begin{array}{l}\text { With } \\
\text { error }\end{array}$ & $\begin{array}{l}\text { Without } \\
\text { error }\end{array}$ & $\begin{array}{l}\text { With } \\
\text { error }\end{array}$ & $\begin{array}{l}\text { Without } \\
\text { error }\end{array}$ & $\begin{array}{l}\text { With } \\
\text { error }\end{array}$ & $\begin{array}{l}\text { Without } \\
\text { error }\end{array}$ & $\begin{array}{l}\text { With } \\
\text { error }\end{array}$ & $\begin{array}{l}\text { Without } \\
\text { error }\end{array}$ & $\begin{array}{l}\text { With } \\
\text { error }\end{array}$ & $\begin{array}{l}\text { Without } \\
\text { error }\end{array}$ & $\begin{array}{l}\text { With } \\
\text { error }\end{array}$ & $\begin{array}{l}\text { Without } \\
\text { error }\end{array}$ \\
\hline $\begin{array}{l}\text { Single-phase to } \\
\text { ground }\end{array}$ & 7.211 & 5.406 & 0.015 & 0.008 & 0.038 & 0.030 & 2.252 & 1.209 & 0.009 & 0.002 & 0.004 & 0.001 & 0.037 & 0.025 \\
\hline $\begin{array}{l}\text { Two-phase to } \\
\text { ground }\end{array}$ & 5.532 & 3.486 & 0.014 & 0.001 & 0.009 & 0.001 & 2.162 & 1.051 & 0.019 & 0.001 & 0.040 & 0.028 & 0.124 & 0.102 \\
\hline $\begin{array}{l}\text { Two-phase } \\
\text { together }\end{array}$ & 2.861 & 0.024 & 0.423 & 0.008 & 0.372 & 0.040 & 1.925 & 0.003 & 0.004 & 0.001 & 0.037 & 0.012 & 0.383 & 0.021 \\
\hline Three phase & 1.053 & 0.325 & 0.044 & 0.004 & 0.023 & 0.002 & 0.671 & 0.0325 & 0.026 & 0.001 & 0.011 & 0.003 & 0.474 & 0.166 \\
\hline
\end{tabular}

detection accuracy of protection schemes. The CT of TYP class has the maximum ratio and phase errors of $10 \%$ and 30 min, respectively [22].

Similarly, capacitor voltage transformers (CVTs) are utilized to provide appropriate voltage signals to relays while they are equipped with ferroresonance suppression circuit (FSC). So, they are not affected by transients of power systems but the same ratio and phase errors appear in the secondary output signals. The CVT of class $3 \mathrm{P}$ has the ratio and phase error of $\pm 3 \%$ and $120 \mathrm{~min}$, respectively for voltages between 0.05 to 1 times of the nominal value [22]

Therefore, the proposed protection scheme performance is evaluated considering CT and CVT errors. At first, for different 20 cases of each fault type (by combination of five different fault resistances including 5, 10, 15 and $20 \Omega$ and four source angle differences of $5,10,15,20,25$ degree), the ratio and phase errors are randomly selected according to the above mentioned error limits and each error is separately added to measured current and voltage. Then, the signals contaminated with errors are used as inputs of the proposed intelligent method. It should be noted that the same classifiers and regression tools which have been trained by exemplar patterns extracted from free-error signals, are utilized for the evaluation purpose.

The obtained results show that in the first stage (fault detection), the proposed method can detect all faults correctly even when CT and CVT have transient behavior. On the other hand, in the second stage (fault location), the mean errors of the fault distance estimation are calculated and provided. In Table 9, the results are given for the operating condition when one line is disconnected and grounded at both sides. The results are provided for different fault types while fault distance varies between 13 and $91 \mathrm{~km}$ from the relay location. In order to provide comparable results, the estimation accuracy is also presented without consideration of CT and CVT errors. It can be clearly seen that the CT and CVT errors have little impact on the accuracy of the proposed intelligent fault location algorithm. In the worst condition, the mean error for single-phase to ground fault at distance of $13 \mathrm{~km}$, increases from $5.406 \%$ to $7.211 \%$. In other fault locations, the effect of measurement errors is ignorable.

Moreover, similar results are provided in Table 10 when both lines are in-service. In all fault distances, the calculated estimation error for both scenarios i.e. with and without consideration of CT and CVT errors are very similar. Thus, the obtained results justify the robustness of the proposed intelligent fault location scheme to measurement errors that are inevitable in real power systems.

\section{Conclusions}

In this paper, a new intelligent method has been presented for the complete protection of parallel

Table 10 The mean absolute percentage error for operating mode in which both lines are in-service considering CT and CVT errors

\begin{tabular}{|c|c|c|c|c|c|c|c|c|c|c|c|c|c|c|}
\hline \multirow{2}{*}{$\begin{array}{l}\text { Fault location } \\
(\mathrm{km}) \\
\text { Fault type }\end{array}$} & \multicolumn{2}{|l|}{13} & \multicolumn{2}{|l|}{26} & \multicolumn{2}{|l|}{39} & \multicolumn{2}{|l|}{52} & \multicolumn{2}{|l|}{65} & \multicolumn{2}{|l|}{78} & \multicolumn{2}{|l|}{91} \\
\hline & $\begin{array}{l}\text { With } \\
\text { error }\end{array}$ & $\begin{array}{l}\text { Without } \\
\text { error }\end{array}$ & $\begin{array}{l}\text { With } \\
\text { error }\end{array}$ & $\begin{array}{l}\text { Without } \\
\text { error }\end{array}$ & $\begin{array}{l}\text { With } \\
\text { error }\end{array}$ & $\begin{array}{l}\text { Without } \\
\text { error }\end{array}$ & $\begin{array}{l}\text { With } \\
\text { error }\end{array}$ & $\begin{array}{l}\text { Without } \\
\text { error }\end{array}$ & $\begin{array}{l}\text { With } \\
\text { error }\end{array}$ & $\begin{array}{l}\text { Without } \\
\text { error }\end{array}$ & $\begin{array}{l}\text { With } \\
\text { error }\end{array}$ & $\begin{array}{l}\text { Without } \\
\text { error }\end{array}$ & $\begin{array}{l}\text { With } \\
\text { error }\end{array}$ & $\begin{array}{l}\text { Without } \\
\text { error }\end{array}$ \\
\hline $\begin{array}{l}\text { Single-phase } \\
\text { to ground }\end{array}$ & 5.773 & 4.858 & 0.685 & 0.069 & 0.080 & 0.014 & 0.939 & 0.293 & 0.309 & 0.001 & 0.014 & 0.011 & 0.728 & 0.445 \\
\hline $\begin{array}{l}\text { Two-phase to } \\
\text { ground }\end{array}$ & 6.250 & 5.478 & 0.036 & 0.021 & 0.034 & 0.020 & 0.442 & 0.070 & 0.035 & 0.007 & 0.142 & 0.010 & 0.609 & 0.375 \\
\hline $\begin{array}{c}\text { Two-phase } \\
\text { together }\end{array}$ & 1.911 & 0.025 & 0.034 & 0.008 & 0.119 & 0.040 & 0.018 & 0.003 & 0.018 & 0.001 & 0.027 & 0.012 & 0.073 & 0.021 \\
\hline Three phase & 1.433 & 0.325 & 0.007 & 0.004 & 0.006 & 0.002 & 0.050 & 0.032 & 0.017 & 0.001 & 0.027 & 0.003 & 0.512 & 0.166 \\
\hline
\end{tabular}


transmission lines. In the proposed method, two main operating modes of parallel lines are considered i.e. when both lines are in-service and when one of the lines is out-of-service and grounded on both sides. In the first step, the fault type as well as faulty phase are identified using a trained PNN. In the second step, the fault location is estimated with the help of several ANNs. The main attribute of the proposed protection scheme is that, the current of the disconnected line which is grounded at both sides is estimated by some ANNs for ground faults on the line in-service because of the mutual zero sequence impedance between parallel lines. Thus, the main attribute of the proposed protection scheme is that, the faults can be located when the disconnected line is grounded at both sides. For each type of fault, a set of certain features are considered to obtain the desirable accuracy. These features have been extracted based on the sequence currents that appear in different fault conditions. Simulation results justify the priority of the proposed method in both aspects of fault type detection and fault location estimation. The proposed protection algorithm is able to detect all fault types correctly and also it yields the average error of about $1.2 \%$ for fault location estimation. Moreover, the accuracy of the proposed intelligent protection scheme is not affected by CT and CVT errors. Therefore, the proposed algorithm can be used in the practical applications as an effective method for parallel lines protection. It should be mentioned that the proposed protection method is applicable only for parallel lines which contribute in the training process.

Authors' Contributions A.H. Azimi: Simulation study, Implementation of the proposed method, Software implementation. A.A. Abdoos: Writer, Technical editor, Analysis of power system simulation and Analysis of obtained results. All authors read and approved the final manuscript.

Funding information The authors acknowledge the funding support of "Babol Noshirvani University of Technology" Grant program Number BNUT/390066/98.

\section{Compliance with Ethical Standards}

Competing Interests The authors declare that they have no competing interests.

Ethical Approval and Consent to Participate Authors justify that names of all contributors involved in the research work have been mentioned in the paper.

Consent for Publication The authors give permission to the journal to publish and share all materials provided in in the paper.

Availability of Data and Materials The test system data can be found in the appendix section. For more information about obtained results please contact authors.

\section{Appendix}

In this study, a part of power system composed of $230 \mathrm{kV}$ parallel lines with a length of $100 \mathrm{~km}$ is simulated in the PSCAD/EMTDC software. The conductor type of the transmission line is Chukar with DC and AC resistances of 0.0097 and $0.0125 \Omega$ respectively. The structure of conductors utilized in parallel lines is shown in Fig. 4. The sequence impedances of parallel lines are given below [2]:

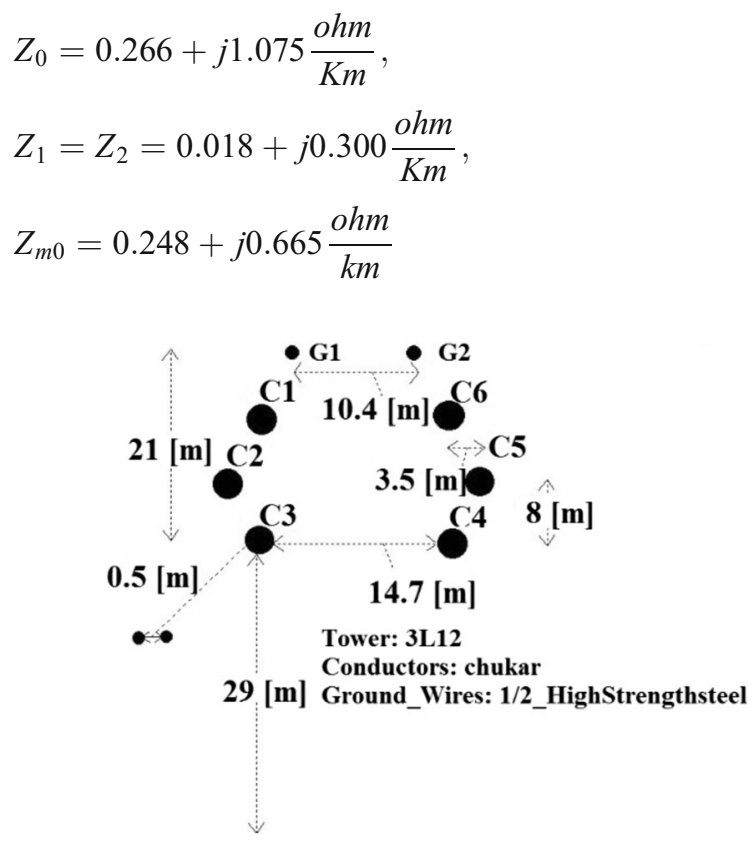

Fig. 4 Structure of conductors in the test system [2]

\section{References}

1. Apostolov, A., Tholomier, D., Sambasivan, S., \& Richards, S., (2007). Protection of double circuit transmission lines. 2007 60th Annual Conference for Protective Relays Engineer, 85-101

2. Sanaye-Pasand M, Jafarian P (2011) Adaptive protection of parallel transmission lines using combined cross-differential and impedance-based techniques. IEEE Transactions on Power Delivery 26(3):1829-1840

3. Gilany MI, Malik OP, Hope GS (1995) A laboratory investigation of a digital protection technique for parallel transmission lines. IEEE Transactions on Power Delivery 10(1):187-193

4. Mansour MM, Swift GW (1986) A multi-microprocessor based travelling wave relay theory and realization. IEEE Transactions on Power Delivery 1(1):272-279

5. Deng F, Zeng XJ, Pan LL (2017) Research on multi-terminal traveling wave fault location method in complicated network based on cloud computing platform. Protection and Control of Modern Power Systems 2(19):1-12

6. Saleem SMA, Sharaf AM (2007) A novel travelling wave based relaying scheme using wavelet transforms for arcing faults detection on series compensated transmission lines. 2007 Canadian 
Conference on Electrical and Computer Engineering (CCECE), $575-578$

7. Sharafi A, Sanaye-Pasand M, Jafarian P (2011) Ultra-high-speed protection of parallel transmission lines using current travelling waves. IET Generation, Transmission \& Distribution 5(6):656-666

8. Sharafi A, Sanaye-Pasand M, Jafarian P (2012) Noncommunication protection of parallel transmission lines using breakers open-switching travelling waves. IET Generation, Transmission \& Distribution. 6(1):88-98

9. Yadav A, Dash Y (2014) An overview of transmission line protection by artificial neural network: fault detection, fault classification, fault location, and fault direction discrimination. Advances in Artificial Neural Systems 2014 (230382):1-20

10. Jongepier AG, van der Sluis L (1997) Adaptive distance protection of double-circuit lines using artificial neural networks. IEEE Transactions on Power Delivery 12(1):97-105

11. Upendar J, Gupta CP, Singh GK (2011) Comprehensive adaptive distance relaying scheme for parallel transmission lines. IEEE Transactions on Power Delivery 26(2):1039-1052

12. Jongepier AG, van der Sluis L (1997) Adaptive distance protection of double-circuit lines using artificial neural networks. IEEE Transactions on Power Delivery 17(1):40-41

13. Heydar-Abadi MM, Foroud AA (2013) Accurate fault classification of transmission line using wavelet transform and probabilistic neural network. Iranian Journal of Electrical \& Electronic Engineering 9(3):177-188

14. Osman AH, Malik OP (2004) Experimental test results for a parallel transmission lines protection scheme using wavelet transform. IET Generation, Transmission \& Distribution 151(6):713-720
15. Hu Y, Novosel D, Saha MM, Leitloff V (2002) An adaptive scheme for parallel-line distance protection. IEEE Transactions on Power Delivery 17(1):105-110

16. Xu ZY, Li W, Bi TS, Xu G, Yang QX (2011) First-zone distance relaying algorithm of parallel transmission lines for cross-country nonearthed faults. IEEE Transactions on Power Delivery 26(4): 2486-2494

17. Jongepier AG, van der Sluis L (1994) Adaptive distance protection of a double-circuit line. IEEE Transactions on Power Delivery 9(3): 1289-1297

18. Paithankar YG, Bhide SR (2003) Fundamentals of power system protection. Prentice-Hall of India Private Limited, 118-152

19. Makwana HV, Bhalja BR (2016) Transmission line protection using digital technology. Springer Verlag, Singapore

20. Witek B (1998) Algorithms of phase and current comparison protection for transmission lines. European Transactions on Electrical Power 8(1):51-56

21. Jayasinghe R, A comprehensive resource for EMTDC, transient analysis for PSCAD power system simulation, 211 Commerce Drive, Winnipeg, Manitoba, Canada R3P $1 A 3$

22. Ziegler G (2011) Numerical distance protection: principles and applications, Erlangen, Germany:Publicis

Publisher's Note Springer Nature remains neutral with regard to jurisdictional claims in published maps and institutional affiliations. 